\title{
TARJETA TURÍSTICA SAFETY AND SECURITY: EL PASAPORTE PARA TURISTAS Y DESTINOS SEGUROS
}

\author{
Danielle Pimentel de Oliveira* \\ Universidad de Valencia \\ https://orcid.org/0000-0003-3572-8002
}

\section{RESUMEN}

La emergencia sanitaria por el COVID-19 ha paralizado el turismo, causando impactos nunca antes imaginados. Más de un tercio de la población global está en situación de confinamiento.

La actividad turística, que supone más del $10 \%$ del PIB mundial, se encuentra en situación de letargo. Se prevén escenarios futuros que requieren de una acción inmediata. La formula Safety Security puede ser la clave de un nuevo orden turístico, que debe contar con mayor número de medidas de sostenibilidad y añadir la seguridad del destino y del turista. Se propone la creación de una tarjeta turística, con credenciales de turista Safety Security para destinos Safety Security.

Palabras clave: COVID-19; turismo; seguridad; destino seguro; tarjeta turística.

\section{Safety and security tourist card: the passport for tourists and safe destinations}

\section{ABSTRACT}

The health emergency caused by COVID-19 paralyzed tourism, causing impacts never before imagined. More than a third of humanity is in a situation of confinement.

The activity that accounts for more than $10 \%$ of the world's GDP is in a state of lethargy. Future scenarios requiring immediate action are predicted. The Safety Security formula can be the key to a new tourism order, which must include sustainability and add to the safety of the destination and the tourist. It is proposed to create a tourist card, with Safety Security tourist credentials for Safety Security destinations.

Keywords: COVID-19; tourism, security; safe destination; tourist card.

Fecha de recepción: 21 de abril de 2020

Fecha de aceptación: 27 de abril de 2020

* Instituto Interuniversitario de Desarrollo Local - IIDL. Universidad de Valencia. España. Email: dapideo@alumni.uv.es 


\section{INTRODUCCIÓN}

El turismo, sin lugar a duda, es el sector más castigado por la crisis sanitaria (también crisis económica, de seguridad y de confianza) producida por el COVID-19, la cual no tiene precedentes en la historia de la humanidad. El sector turístico ha sido duramente golpeado por esta crisis, siendo paralizadas sus actividades a escala mundial, provocando con ello importantes impactos a escala económica y social. Tras más de un mes de cuarentena, se empieza a divisar de forma más racional el tamaño de la catástrofe que se avecina.

La inmovilización del sector a escala global, del tráfico aéreo en más de $90 \%$, de los atractivos, de los hoteles, de la hostelería y de los eventos, ha paralizado también a más de 300 millones de trabajadores (García López, 2020).

Las previsiones auguran que será el último sector en recomponerse de los efectos de la pandemia. Investigadores de la consultora Dcode (2020) elaboraron un estudio exclusivo sobre la región de Egipto, en el cual destacan los potenciales sectores ganadores y perdedores a corto plazo, que bien podría ser extrapolado a escala global, conforme ya viene siendo utilizado por algunos científicos en los diversos webinars realizados a lo largo del mes de abril de 2020 (Figura 1).

\section{Figura 1 \\ ESTUDIO SECTORIAL DE POTENCIALES GANADORES Y PERDEDORES EN EGIPTO}

\section{Dcode DECODING THE ECONOMICS OF COVID-19
\|\|\|\|\|\|\|\|\|\|$\|$
POTENTIAL WINNERS \& LOSERS IN THE SHORT TERM IN EGYPT}

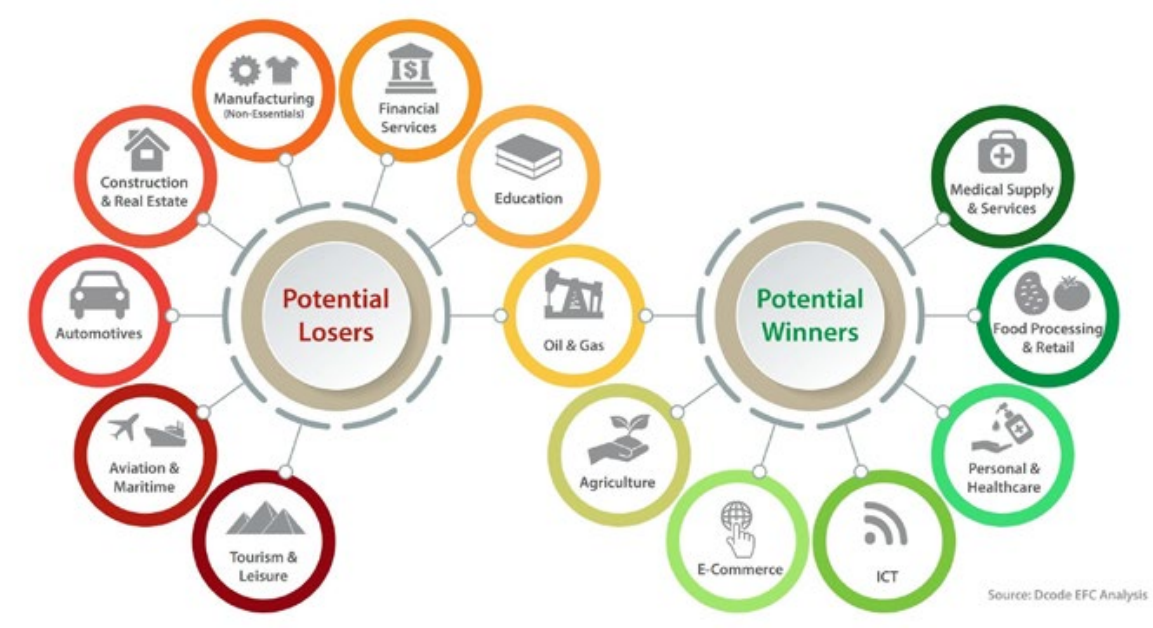

Fuente: Dcode (2020).

Entretanto, cualquier evaluación o estimativa de las repercusiones e impactos de esta crisis en el sector rebasa cualquier realidad, altamente cambiante día tras día. 
Según la UNWTO (2020), y teniendo como referentes el virus SRAS de 2003 y la crisis económica mundial de 2009, las estimativas de llegadas de turistas internacionales podrían disminuir entre un $20 \%$ y un $30 \%$, lo que revertiría en pérdidas de entre 300.000 y 450.000 millones de dólares americanos (Figura 2). Desde otra perspectiva, se habla de "pérdidas equivalentes de entre 5 a 7 años en el número de turistas" (UNWTO, 2020b:8).

\section{Figura 2 \\ PREVISIÓN DE INGRESOS POR TURISMO INTERNACIONAL - 2020, MILES DE MILLONES DE DÓLARES (US\$)}

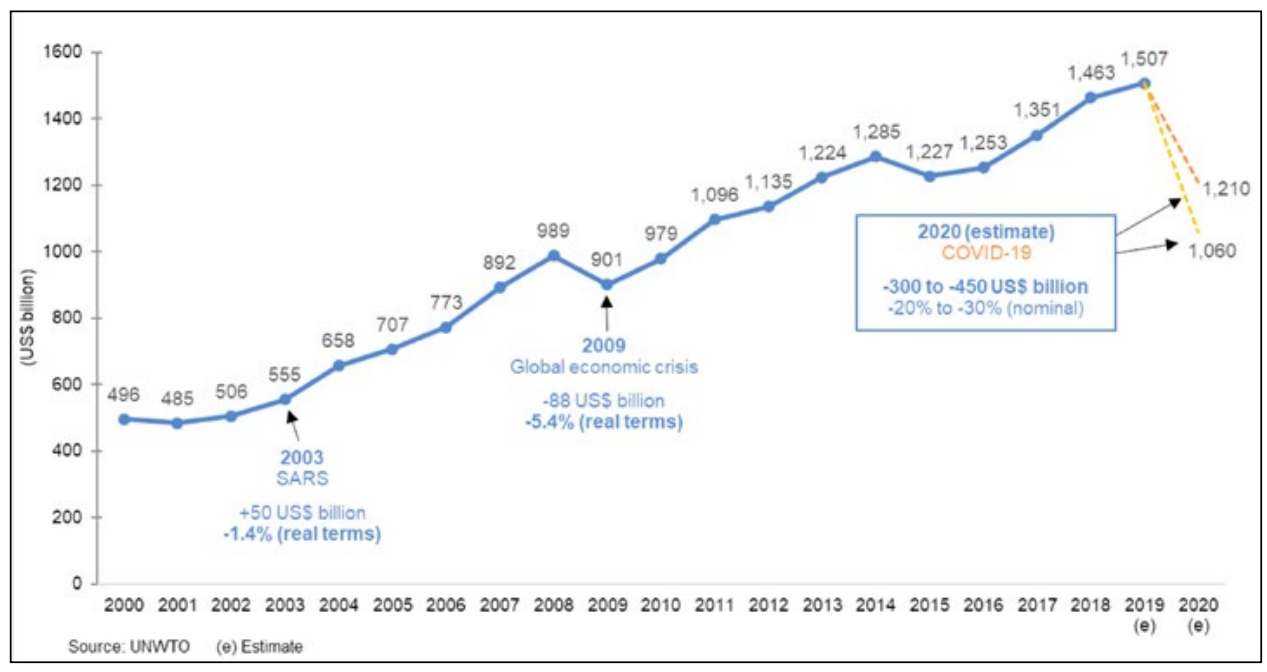

Fuente: UNWTO (2020).

El turismo se caracteriza por ser una actividad segmentada y muy transversal, representando más del $10 \%$ del PIB mundial, que ahora mismo se encuentra en estado de letargo a espera del qué vendrá. Se estima que la zona euro sufrirá una recesión con una bajada del -4\% (García López, 2020). Una situación sin precedentes y absolutamente inesperada a escasos 2 meses atrás, donde la mayor preocupación del sector era el overtourism y mantener o alcanzar su sostenibilidad, (Buhalis apud ON Tourism \& Sustainability, 2020b; García López, 2020; y Vera-Rebollo e Ivars-Baidal, 2020).

Para atajar este problema, la cooperación público-privada va a ser fundamental en el restablecimiento y reflote del turismo (Raúl Hernández apud Universidad de La Laguna, 2020; Vera-Rebollo \& Ivars-Baidal, 2020), que marca, hoy día, cero turistas en la mayoría de destinos (Mancebo apud Convención Internacional de Turismo, 2020). Se sabe que los apoyos, tanto para afrontar los impactos económicos como sociales, están siendo tratados con la intervención de instituciones internacionales del sector, así como con los gobiernos implicados, el sector privado y en algunos casos, con científicos implicados en el desarrollo turístico. 
En la actualidad, más de un tercio de la población mundial está en estado de confinamiento (García López, 2020). Pero, ¿Y si mañana fuera el tan esperado 'Día Después' con la distribución de la vacuna contra el virus a los aproximadamente 7.700 millones de personas en el mundo? ¿Y si el confinamiento fuera levantado para todos los destinos, nacionales e internacionales, y sus fronteras abiertas? ¿Cuál sería el requisito esencial que este 'destino imaginario' debería ofrecer al turista o visitante?, o ¿Cuál sería el criterio para que el turista pudiera entrar en este destino?

Para las regiones más acostumbradas a la vida social, el confinamiento viene siendo una imposición muy dura, pero necesaria. La vuelta, y a semejanza de los países fríos en el retorno del invierno, se espera un mayor ímpetu y ganas de turismo (Vargas-Sanchez, 2020a).

Sin embargo, las miras deben estar proyectadas a corto, medio y largo plazo. Es hora de pensar en el mañana desde un punto de vista real, con planes de acción local a escala global. Costa (apud ON Tourism \& Sustainability, 2020a) afirma que el nuevo paradigma reside en lo local o regional, no solo atraer personas, sino saber gestionar el destino local a través de las visitas de sus residentes y potenciales turistas de las cercanías.

Según Sanz (apud HOSTELTUR, 2020a) y Vargas-Sanchez (2020a), las tendencias apuntan prácticamente a 3 dimensiones. La primera de ellas sería hacia la eminente digitalización. Ya son realidades los tours virtuales, que posibilitan visitar el destino sin salir de casa. Entretanto, esta 'realidad', al mismo tiempo que maravilla a muchos, encasilla a otros tantos destinos que no tienen el alcance tecnológico, y que por ende, suelen ser los más necesitados en lo que se refiere al desarrollo del turismo sostenible (social, económico, político y medioambiental). La segunda dimensión sería el marketing, que seguramente escogerá líneas más sociales, basadas en valores y no tanto en el consumismo, centrado en los principios y en la esencia de las relaciones sociales, con perspectivas más sostenibles. Y la tercera, que según el autor será la clave, es la seguridad, con pautas de cooperación público-privada y requisitos sanitarios que deben apuntar a registros normativos, pero también a la auto-regulación del sector.

Varios estudios científicos prevén diferentes escenarios turísticos para un futuro post COVID-19, desde el más suave hasta el más apocalíptico. Otras instituciones optan por hacer llamamientos a la unión y a la calma. Sin embargo, desde esta investigación, se entiende que la acción debe ser inmediata, aún estando en estado de alarma y en situación de confinamiento. Se hace necesario ponerse en la piel del turista o visitante post COVID-19 y sentir cuáles serán los criterios que el destino deberá cumplir para que este turista, o visitante, pueda volver a confiar otra vez en este destino: “...se hace imprescindible plantear una agenda de trabajo orientada a la creación de turismo, por su carácter de actividad estratégica en el empleo y renta" (Vera-Rebollo \& IvarsBaidal, 2020).

Un nuevo orden turístico se aproxima, el cual deberá contar, además de la mencionada sostenibilidad (a través de la guía fiable diseñada en la Agenda 2030, con los 17 ODS), con la seguridad. Sin embargo, esta seguridad ya no es la que conocíamos, requerirá de un doble sentido, desde el destino para con el turista y desde el turista para con el destino: "La economía puede que esté dañada, pero el primer freno será el miedo" (Linares apud HOSTELTUR, 2020b). 
Por ello, este estudio propone la creación de una tarjeta turística única e internacional, con las credenciales idóneas para ser aceptado como turista Safety and Security en destinos que presentan características regladas y normativa clara en el control de COVID-19, es decir, destinos y establecimientos Safety and Segurity.

\section{LA COOPERACIÓN NECESARIA}

Las devastadoras consecuencias del COVID-19 para el sector turístico animan a que las entidades gubernamentales, tanto nacionales como internacionales, el sector privado y el sector académico, cooperen y unan fuerzas a favor de restablecer la cadena de valor del turismo.

Para que el turismo desarrolle todo su potencial para ayudar a las sociedades y países enteros a recuperarse de esta crisis, nuestra respuesta debe ser rápida, coherente, unida y ambiciosa, (Pololikashvili apud UNWTO, 2020d).

Por ello, la UNWTO (2020a) y la OMS se han unido en un llamamiento a la responsabilidad y a la coordinación. NECSTouR (2020) creó un portal que recoge informaciones y tendencias mundiales, así como conocimientos regionales y evaluaciones de impactos, con el propósito de generar un foro de cooperación. También, desde de la UNWTO (2020c) se ha lanzado un llamamiento a las empresas y empresarios para participar en la creación de soluciones sanitarias, económicas y de gestión del destino.

El Ministerio de Industria, Comercio y Turismo, juntamente con el Ministerio de Sanidad, a su vez, desarrollaron un informe denominado 'COVID-19, guía de buenas prácticas para los establecimientos y trabajadores del sector turístico' (MINCOTUR, 2020), en el cual se busca dar respuestas a las inquietudes generadas en el sector, a través de recomendaciones e instrucciones.

Asimismo, la UNWTO (2020d) divulgó, quizás, la más contundente de las convocatorias, una serie de veinte y tres recomendaciones, divididas en tres áreas clave: 1) Gestión de la crisis y mitigación del impacto; 2) Proporcionando estimulo y acelerando la recuperación, y 3) Preparación para el mañana; entre otras acciones.

Sin embargo, los ejemplos citados y otros más, son llamamientos sin un plan de acción concreto, que acaban por transformarse en una declaración de intenciones y recomendaciones, sin más.

Se entiende que las acciones para el establecimiento de un turismo seguro y sostenible deben ocurrir todavía en el estado de alarma, en la actual coyuntura del "pre-retorno" en el que se encuentran la gran mayoría de los destinos turísticos.

La planificación del retorno a la actividad es necesaria, pero desde bases solidas y con estructuras que garanticen su desarrollo a medio y largo plazo, asegurando que los rebrotes no vuelvan a surgir a partir de contagios externos al destino (los llamados contagios importados). Según Hernández Martín (2020:1): "la probabilidad de rebrotes o mutaciones del virus marcarán los escenarios actuales y futuros".

Lo primero es tener claro que el turismo, afortunadamente o no, ya no será el mismo, ni por parte de los turistas y visitantes, ni por parte de los destinos y Stakeholders (Vera- 
Rebollo \& Ivars-Baidal, 2020). García López (2020) incide en una nueva normalidad, que no será igual en todos los destinos y que tardará, seguramente, más de un año en establecerse de forma definitiva.

Las principales herramientas capaces de minimizar el impacto de la crisis y el alcance económico y social que ésta vaya a generar deben ser establecidas a partir de las políticas públicas de intervención, fundamentales en la transición y recuperación de la economía, y el poder de adaptación del sector privado a las mismas.

\section{LOS ESCENARIOS POST COVID-19}

Tras los grandes alardes de la utilización del big-data y de sus posibilidades de predicción de "hasta 3 meses de anticipación" y hasta el "90\% de acierto", llega la hora de pasar a la realidad, y no la virtual. Nunca se ha vivido algo parecido, las predicciones no llegaron a prever la catástrofe, el COVID-19 vino para darnos un baño de humildad y asentar el polvo de la hiperconectada economía con información ultrarrápida y 'fiable' (Vargas-Sanchez, 2020a:1).

La crisis sanitaria marcará un antes y un después en relación a nuestra sensación de seguridad, convivencia, experiencia y exigencia de un destino. La sensación de incertidumbre por la cual pasa el sector, le hace más proclive a diseñar escenarios de supervivencia que a desdibujar opciones de salir de la crisis. Es por ello que surge la necesidad de imaginar o prever qué puede pasar en el futuro del sector.

Vargas-Sanchez (2020b) apuesta por la perspectiva estructural y coyuntural, en la que los escenarios estarían vinculados a las restricciones por parte del gobierno y la cautela y sensibilidad frente a la seguridad y a la salud por parte del turista, respectivamente. Navarro Jurado et al. (2020) formulan cuatro escenarios a partir de niveles de destrucción de la riqueza y sufrimiento. Partiendo desde un escenario más optimista con vistas al mes de mayo y reapertura del $70 \%$ de comercio y del sector, $30 \%$ de quiebra de los negocios turísticos, además de una reacción no negativa por parte de los residentes a recibir turistas. Otro escenario sería el moderado, con reapertura del $50 \%$ a partir de julio, con $50 \%$ de quiebra de los negocios y reacción desigual a recibir turistas. Uno distinto a ese, denominado pesimista, con $30 \%$ de reapertura a partir de septiembre, $70 \%$ de quiebra de los negocios y reacción negativa ante el recibimiento de los turistas. Y el último, calificado de caótico, con reapertura del $30 \%$ del comercio y del sector, quiebra del $80 \%$ de los negocios relacionados con el sector turístico y reacción a recibir los turistas muy negativa por parte de los residentes.

Por otro lado, García López (2020) afirma que la recuperación del sector se realizará en dos etapas. Primeramente, el turismo nacional y de cercanía; y más tarde, contará con el turismo internacional. A esta afirmación, Costa (ON Tourism \& Sustainability, 2020a) refuerza la idea de que hasta finales de agosto de 2020 se retomará el turismo domestico; a comienzos del primer semestre de 2021 se empezarán a ver viajes por Europa; y a finales de 2021, el inicio de los viajes de larga distancia.

El FMI, a su vez, analiza hasta tres escenarios de futuro a partir de la desviación del PIB mundial (Cinco Días, 2020). El primero, cuenta con confinamientos hasta el segundo semestre y gradual desescalada, prevé un impacto de tres puntos y una caída del $6 \%$, 
con aumento de las primas de riesgo y endurecimiento de las condiciones financieras. El segundo toma en cuenta la contención de la pandemia y un rebrote en 2021. Según el FMI, en el año 2021 el efecto sería muy dañino, y con una previsión de caída de hasta cinco puntos y más tres puntos en 2022. El tercero, el peor escenario, combina las dos alternativas, el PIB caería el doble de lo previsto (6\%), y el año que viene otros ocho puntos, perdiendo de 2022 a 2024 otros catorce puntos. Ese último escenario presentaría fuertes aumentos del gasto público, del déficit y de la deuda.

Hernández-Martín (2020) analiza un conjunto de escenarios que presentan cuatro dimensiones interrelacionadas entre sí. La primera de ellas sería la dimensión sanitaria, y según el autor esta dimensión presenta aspectos estratégicos y estará altamente vinculada con la creación de la vacuna y/o desarrollo de tratamientos eficaces y el grado de inmunidad de las personas ya infectadas. La segunda dimensión es relativa a la movilidad, que limita uno de los aspectos fundamentales para el turismo, tanto desde el destino como desde el origen, dependerá de las desescaladas y relajamiento de las restricciones de movilidad. Según el autor, esta dimensión presentará aspectos graduales, empezando inicialmente a escala local y regional en segundo plano, y más tarde extendiéndose a países y atingiendo a la escala global. La tercera dimensión es la económica, que repercutirá de forma profunda en el poder adquisitivo de los turistas o visitantes. Por último, la cuarta dimensión cuenta con el cambio en el comportamiento de los turistas y en su forma de hacer el viaje.

Otros tres escenarios, en base a previsiones de Deloitte (2020:1), estarían relacionados con la evolución y desarrollo y con el control del virus. En este estudio, la consultora afirma que en el primer escenario: 'El año del coronavirus', a cada rebrote que se produzca, en paralelo se produciría una desaceleración en la producción de la zona de contagio, que se traduciría, en un mundo globalizado, en una perturbación de la actividad económica que desaceleraría considerablemente el crecimiento mundial. En un segundo escenario: 'El coste de una respuesta global al coronavirus', los centros económicos de todo el mundo estarían sujetos al cierre, con el consecuente pánico a nivel mundial por la propagación de la pandemia. Este escenario se daría debido a acciones descoordinadas entre países y entidades (públicas y privadas) que interrumpirían el flujo de bienes, mercancías y personas, produciéndose un descenso en la producción. Todavía, según Deloitte, el turismo y las empresas vinculadas al sector "se verían fuertemente afectadas y disminuirían drásticamente su volumen de ingresos”. El tercer escenario: 'La crisis del sistema financiero', los retrasos de la producción generarían problemas financieros para las empresas, generando grandes deudas.

Sea como fuere, e inmersos en este entorno (altamente) VUCA $^{1}$ (Valderrama, 2019), donde la realidad perece una ficción con planes de confinamiento al 'estilo hollywoodiano', la sensación de seguridad toma otra dimensión. La seguridad que conocemos ya no parece ser suficiente ni para el turista ni para el destino, hay que extrapolar este contexto y ofrecer y exigir un ámbito Safety and Security. En este sentido, García López (2020) afirma que no será hasta el verano de 2021, cuando se podrá comprobar si realmente el

1 VUCA: Acrónimo de origen militar (USA Army War College); V-volatilidad; U-incertidumbre (uncertainty); C-complejidad; A-ambigüedad. 
turista se sentirá, o no, seguro para realizar viajes de forma intensa y a destinos de larga distancia. Y la pregunta que la mayoría se hace es: ¿Aguantaría la economía un año sin contar con el turismo?

\subsection{Safety and Security en un entorno turístico}

Los términos Safety y Security presentan diferencias en el concepto de las dos palabras, aunque en español presenten el mismo significado de seguridad. Al analizar los vocablos desde sus orígenes anglófonos, se entiende que la palabra Safety se traduce como protección y Security como seguridad. Olleros (2017:1), desde una óptica más neuro-científica, indica que el concepto de seguridad está fuertemente "vinculado con la tranquilidad y por ende, seguridad es la sensación de sentirse seguro y al mismo tiempo, la certeza de estarlo".

En otras palabras, son acciones diseñadas de forma conjunta, un sistema para operaciones diarias 'normales' y situaciones inesperadas 'anormales'. Desde un prisma más turístico, podríamos afirmar que Safety estaría relacionado a señales de advertencia, como las banderas rojas o verdes de las playas. Por otro lado, Security hace referencia a medidas de protección, como por ejemplo control de pasaporte y aduanas, o las barreras de protección en un evento.

Vera-Rebollo y Ivars-Baidal (2020) resaltan que determinados destinos cercanos que sepan afianzar las claves de seguridad como elemento de competitividad, tendrán sin lugar a dudas, una valoración creciente entre los visitantes. Por ello, se entiende que los destinos, así como empresas vinculadas, o no, al sector, deberían replantear estrategias de colaboración de forma conjunta, para diseñar nuevas formas de relacionarse con el turista.

La resiliencia del turismo, una actividad que fue capaz de sobreponerse a las adversidades del entorno, sean ellas sociales, económicas o ambientales, debe ser ahora trasladada a los destinos y a sus Stakeholders. Se hace necesario el desarrollo de ciudades más resilientes frente a entornos de crisis como la actual.

El manual 'Cómo desarrollar ciudades más resilientes' (UNISDR, 2017), creado para el período 2015-2020, señala hasta diez aspectos esenciales para lograr ciudades resilientes, tales como: 1. Organizarse para la resiliencia frente a los desastres; 2 . Identificar, comprender y utilizar los escenarios de riesgo actuales y futuros; 3 . Fortalecer la capacidad financiera para la resiliencia; 4. Promover el diseño y desarrollo urbano resiliente; 5. Proteger las zonas naturales de amortiguación para mejorar la función de protección proporcionada por los ecosistemas naturales; 6. Fortalecer la capacidad financiera para la resiliencia; 7. Comprender y fortalecer la capacidad social para la resiliencia; 8. Incrementar la resiliencia de la infraestructura; 9 . Asegurar la afectividad de la preparación y la respuesta en casos de desastre; 10. Acelerar la recuperación y reconstruir mejor.

La efectiva aplicación de estos diez aspectos esenciales pasa por la participación en la promoción de la resiliencia, a través de la organización y cooperación de las partes interesadas. Comprendiendo y evaluando el riesgo, a través de herramientas de autoevaluación y del establecimiento de un plan de acción que cuente con el apoyo, financiación, vigilancia y seguimiento. 


\subsection{Destino Safety and Security}

Ya no se habla más de terrorismo o de inestabilidad social, la gran preocupación es por la seguridad en la salud. Percibir un destino, sus establecimientos y sus atractivos como seguro y con máximas garantías sanitarias será el atributo esencial que exigirá el futuro turista post COVID-19.

Es en este escenario, las ciudades más resilientes y sobre todo las Smart Cities ganan más protagonismo, jugando el papel de garante y estabilizador de la economía y de la inseguridad percibida. "No hay turismo sin que antes el turista tenga la seguridad de que el destino es seguro", afirmaba Ricardo Zambrano, Ministro de Turismo de Ecuador (Convención Internacional de Turismo, 2020).

Vargas-Sanchez (2020c), afirma que será fundamental que los destinos y sus Stakeholders sean capaces de transmitir seguridad para que la recuperación de la actividad turística ocurra de forma efectiva. De igual forma, es importante observar las reacciones de rechazo al turista por la concentración de personas o por procedencia del turista.

Es en este sentido que un resumen ejecutivo realizado por Mabrian Technologies (2020) en referencia a los efectos de la crisis sanitaria en España, demuestra, a partir del análisis de datos de las redes sociales, que el destino España viene sufriendo un continuo descenso a nivel global de la percepción de seguridad por parte del turista. Destaca además la alta sensibilidad a la inseguridad percibida por los ingleses (-70\%), los franceses $(-61 \%)$, y por los alemanes $(-54 \%)$, mercados clave para el sector turístico español. La contracción del mercado exterior supone un gran impacto económico en los destinos, ya que suelen realizar un mayor gasto medio diario con estancias medias superiores a las nacionales (Vera-Rebollo \& Ivars-Baidal, 2020).

Es esencial entender que únicamente con el mercado interior no sería posible compensar la llegada de los 83,7 millones de turistas extranjeros de 2019 (INE, 2020). Por ello es fundamental evitar las situaciones de rechazo, tanto desde el turista por el destino, como desde el residente por el turista, y todo ello depende del tipo de estrategias y acciones llevadas a cabo y planificadas hoy, en el estado de alarma.

\subsection{Movilidad Safety and Security}

Algunos de los aspectos, quizás, más relevantes de la crisis sanitaria para el turismo sería la disolución de las restricciones de movilidad. Algunos estudios (Navarro Jurado et al., 2020; Hernández Martín, 2020) afirman que este aspecto tendrá una característica escalonada pero progresiva.

Las compañías aéreas, otro de los sectores duramente afectados, tienen por delante un largo vuelo de vuelta hacia sus principios y a la humanización de sus servicios. La 'magia' del Lowcost deberá ser replanteada, sin lugar a dudas.

La ‘democratización de los viajes en avión’ que llegó de la mano de los servicios aéreos Lowcost, pasará, a partir del COVID-19, por un proceso de reestructuración, y ese 'derecho a la movilidad adquirido' tendrá un carácter más bien estratégico, ya que los medios de transporte, sean aéreos, terrestres o marítimos, deberán aplicar medidas de seguridad e 
higiene que garanticen la prestación de sus servicios, tal como afirma la Dra. Sealy (ON Tourism \& Sustainability, 2020b) y García López (2020).

Las ventajas con que contaba el servicio aéreo Lowcost, de rapidez en el servicio, a expensas del espacio o comodidades, ahora contará con el hándicap de las exigencias de mascarillas, higienización profunda, no solo en los aviones sino también en los aeropuertos, además del inevitable distanciamiento entre los pasajeros, mayor tiempo en tierra y aumento de costes que será trasladado, obviamente, a los billetes. Lo que según Gabriel Escarrer (apud Ventaynol, 2020), vice presidente y CEO de Meliá Hotels Inernational, será inviable económicamente.

En este sentido, algunas empresas aéreas ya empiezan a anticiparse. Emirates ya hace test del COVID-19 a todos sus pasajeros (La Vanguardia, 2020b), adelantándose así a las peticiones de los países que requieran tales certificados del test para recibir a los viajeros. Gabriel Escarrer (apud Ventaynol, 2020), afirma que la tendencia será la realización de test rápidos a los viajeros, para vender seguridad al turista.

En este sentido, Hernández-Martín (2020:1) recuerda muy acertadamente que "los turoperadores podrían jugar un papel positivo en esta etapa de transición por su capacidad para activar el mercado y sus alianzas con el sector turístico".

La gran incógnita es si estos tipos de prevenciones también serán factibles desde la movilidad terrestre y fluvial, ya que según García López (2020), en una primera fase de recuperación, se primarán los transportes privados frente a los transportes públicos. El autor también prevé que el sector crucero tardará en reponerse, en contrapartida, los viajes de auto-caravana aumentarán.

\subsection{Alojamiento Safety and Security}

Según el último informe del Ministerio de Industria, Comercio y Turismo (MINCOTUR, 2020), las autoridades todavía no han establecido protocolos específicos de prevención para los hoteles.

Gabriel Escarrer (apud Ventaynol, 2020) señala que es muy probable que la temporada turística de este año será negativa y que la hibernación del sector hotelero, con una fuerte dependencia de los mercados exteriores, será inevitable hasta que no se encuentre la vacuna del COVID-19. Lo que marcará profundamente la forma como serán realizados los viajes y el relacionamiento entre las personas (García López (2020).

Hernández-Martín (2020:1) y Vera-Rebollo y Ivars-Baidal (2020) resaltan que el posible cambio de comportamiento de los turistas, "a los que se debería acompañar muy de cerca", unido a la caída del poder adquisitivo de los visitantes, puede condicionar las preferencias de los consumidores hacia la elección o modalidades de alojamiento. En este sentido, España cuenta con una gran desventaja en referencia al cambio de mentalidad, ya que se presupone que los turistas buscarán destinos donde la intensidad de la pandemia no haya sido tan aguda (García López, 2020). Este último autor también afirma que en una primera fase, las viviendas o apartamentos turísticos tendrán una mayor procura, respecto a los hoteles. Y que la demanda de alojamientos boutique y pequeños, de entornos rurales y alejados, presentará mayor protagonismo. 
Anticipándose a esta situación, el gobierno de Barcelona lanza la certificación que identificará a los establecimientos libres del COVID-19, y el gobierno de Madrid impulsa la creación de certificados hoteleros, denominados 'Hoteles COVID Free', ambas acciones direccionadas a garantizar la seguridad de los clientes y trabajadores del sector (La Vanguardia, 2020a; Tourinews, 2020).

Entretanto, se obvian las necesidades de los residentes, y esta situación es más crítica, ya que no se trata únicamente de necesidades, sino de la seguridad del destino. Se obvian los niveles de satisfacción del residente como aspectos determinantes y parte de la experiencia turística y como factor de riesgo en el combate a la turismofobia. En este sentido, Vera-Rebollo y Ivars-Baidal, (2020:4) recuerdan los conflictos entre residentes y turistas a escala local, debido al desplazamiento a sus segundas residencias, en las etapas previas al confinamiento, y destacan que son la "expresión más clara de las nuevas relaciones de convivencia en los destinos turísticos que se derivan de la pandemia... [que] van a estar presentes al menos hasta que ésta haya sido superada".

Por otro lado, aplicando únicamente los certificados a los hoteles, quizás no sea posible mantener la garantía de que los turistas internos y visitantes no sean COVID-19 positivo. La utilización de test rápidos en aeropuertos, estaciones de trenes y autobuses ( ¿ ¿Y centrales de reserva de alquiler de coches y estaciones de servicio?!) no parecen acciones factibles, y simplemente no condicen con la realidad del nuevo orden turístico que empieza a instalarse, con un marcado acento en el mercado local y de cercanía que normalmente viaja en coche privado.

\section{LA TARJETA TURÍSTICA 'SAFETY AND SECURITY'}

La propuesta de la presente investigación se basa en el mantenimiento de la seguridad y en la transmisión y repercusión de la misma al turista y al residente. Se busca con ella crear un ámbito turístico que sea seguro para el turista, y que mantenga esta seguridad también a los residentes locales, verdaderos soportes de la actividad turística.

Acciones descoordinadas por parte de empresas pueden llevar a escenarios incompatibles y colapso del sistema a medio plazo. En consecuencia, la cooperación público-privada sería, quizás, la clave para la recuperación del sector turístico (Raúl Hernández apud Universidad de La Laguna, 2020; Gabriel Escarrer (apud Ventaynol, 2020).

\subsection{De la escala supra nacional a la escala local}

La declaración conjunta sobre el turismo y el COVID-19 realizada por la OMT y por la OMS (UNWTO, 2020a) se constituye en una de las primeras acciones llevadas a cabo por los máximos órganos del sector a escala supranacional.

De igual forma, y a escala nacional, el desarrollo de la guía de buenas prácticas para los establecimientos y trabajadores del sector turístico (MINCOTUR, 2020) elaborada de forma conjunta por el Ministerio de Industria, Comercio y Turismo y Ministerio de Sanidad, y con la colaboración de varias entidades, tales como la Asociación Empresarial Hostelera de Benidorm, Costa Blanca y Comunidad Valenciana - HOSBEC, CCOO, UGT, 
CEOE y CEPYME, acaban por constituirse como ejemplos de acuerdos bilaterales que deberían extenderse a las demás escalas regionales y locales.

Por otro lado, la cooperación a escala local debe contar con el apoyo del gobierno nacional, proporcionando, además de los test rápidos a toda la población, espacios para la regulación de medidas de prevención aplicables a todos los sectores, a modo de protocolos comunes de acción, que se extiendan de forma específica para el sector hotelero, y demás sectores vinculados al turismo (transporte, restauración, atracciones...) a escala regional.

Entretanto, la política de comunicación debe ser fluida y clara, entendible y participada de forma transversal. Con el fin de generar confianza, transparencia y sobre todo respetar la idiosincrasia y mantener la confianza y seguridad de la población local (Vera-Rebollo \& Ivars-Baidal, 2020).

Por ello, la creación de la tarjeta turística Safety and Security, que contiene la información que proporcionan estos aspectos necesarios para el desarrollo de un turismo seguro y sostenible, viene de encuentro a las necesidades sociales, económicas y sanitarias exigidas, a día de hoy, no solo por gobiernos, sino por la población local en cuanto receptores del turismo, agentes del sector y por el propio turista.

\subsection{Aspectos de la tarjeta turística}

La tarjeta turística Safety and Security, inicialmente, contaría con la información básica respecto al estado de salud del visitante relacionado al coronavirus, indicando si el turista o visitante es inmune a la enfermedad, si es COVID-19 negativo, o en un futuro, si ya está vacunado contra el virus. La tarjeta también presenta ventajas a largo plazo, ya que tras la finalización de la pandemia (sea por la elaboración y distribución de la vacuna o anticuerpos), seguirá vigente, pudiendo incorporar informaciones útiles, tales como especificaciones y exigencias sanitarias de cada país o controles de vacunación necesarios para el visado y/o acceso (vacuna contra tétano, malaria...).

Su aplicación debería contar con criterios sanitarios de aceptación a nivel internacional, a partir de certificados médicos.

Esta tarjeta se desarrollaría en dos etapas. Por un lado, con planes de acción estructurales a corto plazo, y por otro lado, con planes de acción coyunturales, contemplando en una segunda esfera la promoción y la atracción del turismo hacia el destino.

La primera etapa, caracterizada por su aspecto estructural, cuenta con la participación acentuada de órganos institucionales, desde la escala local a la escala internacional. Esta etapa estaría volcada a la contención de la pandemia, garantía de seguridad, información y transmisión de seguridad, además de la manutención del turismo, desde aspectos económicos y sociales a corto plazo.

En esta etapa, la tarjeta turística serviría como un garante del turista a modo de salvoconducto. Con esta acción se busca dar la seguridad exigida por los residentes, transmitiendo seguridad y a la vez confianza en la llegada de los turistas. Con la utilización de esta tarjeta, se evitarían rechazos por parte de los turistas que visitan el destino, así como acciones relacionadas con la turismofobia por parte de los residentes. 
La segunda etapa, con aspectos más coyunturales, contaría con la participación de expertos en marketing y promoción del destino. En esta etapa la promoción local daría paso a la internacional y entraría en una fase decisiva de recuperación del mercado exterior. Por ello se aplicarían sellos o puntos a cada turista, relacionados con aspectos deseables, tales como conocimiento y aplicación del turismo sostenible y respeto por la cultura local. Los puntos serían canjeados por descuentos en establecimientos hosteleros, eventos, etc., además de facilitar accesos a salas vips en aeropuertos y otras comodidades.

$\mathrm{Su}$ desarrollo y planificación dependerían de acuerdos entre el sector privado, tanto de empresas vinculadas con la industria turística como otras que podrían ofrecer servicios o prestaciones, partiendo desde una escala supranacional y hasta la local.

\section{CONCLUSIONES}

Tras el anuncio del Ministerio Español de Trabajo, Migraciones y Seguridad social, del día 19 de abril de 2020, en el cual la Ministra Yolanda Díaz declaró, de forma enfática, que el turismo no podría reactivarse hasta finales de año, saltaron las alarmas.

La Mesa del Turismo ${ }^{2}$ alertó que si esto realmente sucediera, supondría la quiebra de miles de empresas turísticas, de sus proveedores y la pérdida de miles de puestos de trabajo. Sin embargo, resaltó que la situación se podría ver amenizada, no del todo, si se llegaran a permitir los viajes internos con la habilitación de un 'pasaporte sanitario', sugerencia también resaltada por el CEO de Hoteles Meliá International.

A partir de esto y de un análisis profundo en la actualidad turística a escala internacional, se entiende que la necesidad de un salvoconducto a los turistas es eminente. Entretanto, este 'pasaporte' debe venir acompañado de medidas en pro del destino y de los residentes, a través de protocolos comunes de actuación en colaboración público-privada.

Esta 'tarjeta-pasaporte' debe actuar desde una doble vertiente, social y económica, aportando económicamente a las empresas del sector y sus proveedores, y actuando como una fuente de tranquilidad y respaldo a todos los Stakeholders.

La tarjeta Safety and Security viene a desarrollar este papel y abrir posibilidades futuras de un desarrollo turístico adecuado, cumpliendo con requisitos indispensables para la creación de un turismo sostenible y respetuoso con el entorno local.

Las posibilidades son infinitas, y en un momento tan crítico en el sector turístico a escala global, los gobiernos deben empezar a contar con su activo más valioso, la capacidad de los profesionales de turismo; sus conocimientos científicos y técnicos pueden aportar soluciones reales para afrontar los desafíos del post-COVID-19.

Ya no hay espacios para una declaración de intenciones, es hora de actuar, de actitudes firmes y osadas, pero realistas. Imaginar y crear el futuro del turismo desde espacios multilateralistas no basta, es necesario aplicar el multilateralismo con vistas a lo local.

Más que nunca la resiliencia del sector turístico podría salir reforzada, demostrando su importancia, pero no solo a escala económica, sino social, política y medioambiental.

2 La Mesa del Turismo es un grupo de encuentro, de diálogo y de creación de estados de opinión, formado por una serie de personalidades del sector privado turístico español. https://mesadelturismo.org/nosotros/. Último acceso: 19/04/2020. 


\section{REFERENCIAS}

CINCO DÍAS (2020): "El FMI avisa de tres escenarios en los que la crisis será aún mucho peor". Cinco Días, 15 de abril de 2020.

CONVENCIÓN INTERNACIONAL DE TURISMO (2020): Reinventando el turismoGestión de una crisis [Educación; Vídeo]. Discover CIT. https://www.facebook.com/ DiscoverCIT/videos/902210453562022/

DCODE (2020): Infographics -Decoding The Economic of COVID-19. Dcode Economic \& Financial Consulting. https://dcodeefc.com/infographics

DELOITTE (2020): El impacto económico del COVID-19: Los efectos económicos del COVID-19 y los posibles escenarios globales en función de su desarrollo. Deloitte. https://www2.deloitte.com/es/es/pages/about-deloitte/articles/impacto-economico-delcovid19.html

GARCÍA LÓPEZ, R. (2020): ¿Cómo será el turismo tras la crisi del COVID-19? Aprende de turismo. https://www.aprendedeturismo.org/recuperacion-turismo/

HERNÁNDEZ-MARTÍN, R. (2020): "Entender y afrontar la crisis turística", El Día. https://www.eldia.es/opinion/2020/04/10/entender-afrontar-crisis-turistica/1069164. html

HOSTELTUR. (2020a): Destinos Españoles, ciudades: Madrid, Barcelona y Valencia. https://www.hosteltur.com/webinar/destinos-espanoles-ciudades-madrid-barcelona-yvalencia

HOSTELTUR. (2020b): Destinos españoles: Costas e Islas [Educación; Vídeo]. https:// www.youtube.com/watch?v=Vfpqg1S35I8

INE. (2020): Estadística de Movimientos Turísticos en Fronteras (FRONTUR). https:// www.ine.es/daco/daco42/frontur/frontur1219.pdf

LA VANGUARDIA (2020a): El Gobierno dará un sello turístico a los alojamientos libres de coronavirus, 17 de abril de 2020. https://www.lavanguardia.com/economia/20200417/48567686102/el-govern-dara-un-sello-turistico-a-los-alojamientos-libres-de-coronavirus.html

LA VANGUARDIA (2020b): Emirates hace el test de la Covid a todos sus pasajeros, 16 de abril de 2020. https://www.lavanguardia.com/economia/20200416/48550192533/ emirates-tests-coronavirus-todos-pasajeros.html

MABRIAN TECHNOLOGIES (2020): Resumen ejecutivo efecto de la crisis COVID-19. Destino: ESPAÑA. Mabrian Technologies. https://blog.mabrian.com/es/2020/04/17/ resumen-efectos-covid19-destino-espana/

MINCOTUR. (2020): COVID-19: Guía de buenas prácticas para los establecimientos y trabajadores del sector turístico. Gobierno de España. https://www.mincotur.gob. es/es-es/gabineteprensa/notasprensa/2020/documents/nueva\%20gu\%C3\%ADa\%20 de\%20buenas\%20prácticas\%20covid-19.pdf

NAVARRO JURADO, E., ORTEGA PALOMO, G. y TORRES BERNIER, E. (2020): Propuesta de reflexión desde el turismo frente al COVID-19: Incertidumbre, impacto y recuperación. Instituto Universitario de Investigación de Inteligencia e Innovación Turística. http://www.i3t.uma.es/index.php/2020/03/30/tres-investigadores-del-i3t- 
uma-publica-un-documento-de-debate-denominado-reflexiones-desde-el-turismofrente-al-covid-19-incertidumbre-impacto-y-recuperacion/

NECSTOUR (2020): Facing together coronavirus covid-19. MyNECSTouR. https://necstour.eu/Coronavirus

OLLEROS, A. (2017): Diferencias entre Seguridad, Safety y Security. ÁO - Ángel Olleros. https://www.angelolleros.com/diferencias-seguridad-safety-security/

ON TOURISM \& SUSTAINABILITY. (2020a): E1 Impact \& Challenges on UN Sustainable Development Goals [Entretenimiento; Webinar]. Jornal on Tourism Sustainability. https://www.youtube.com/watch?v=4_L3xMx_Fg

ON TOURISM \& SUSTAINABILITY (2020b): E2. Impact \& Challenges on UN Sustainable Development Goals [Entretenimiento; Webinar]. Jornal on Tourism Sustainability. https://www.youtube.com/watch?v=xi1DCYKG9Ho\&feature=emb_logo

TOURINEWS (2020): "Hoteles COVID Free», el certificado que avala la seguridad en los hoteles de Madrid. https://www.tourinews.es/resumen-de-prensa/notas-de-prensaempresas-turismo/hoteles-covid-free-certificado-avala-seguridad-establecimientosmadrid_4459914_102.html

UNISDR. (2017): Cómo desarrollar ciudades más resilientes. Manual para líderes de los gobiernos locales - 2015-2020. United Nations Office for Disaster Risk Reduction UNISDR. https://eird.org/americas/docs/manual-para-lideres-de-los-gobiernos-locales. pdf

UNIVERSIDAD DE LA LAGUNA (2020): Reflexiones y perspectivas del turismo en Canarias para las salidas de la crisi del COVID-19 [Formación; Webinar]. Fyde Cajacanarias. https://www.youtube.com/watch?v=Dn50-4fj11g

UNWTO. (2020a): Declaración conjunta sobre el turismo y el COVID-19-La OMT y la OMS hacen un llamamiento a la responsabilidad y la coordinación. UNWTO - Organización Mundial del Turismo. https://www.unwto.org/es/news/covid-19-omt-omsllamamiento-a-la-responsabilidad-y-la-coordinacion

UNWTO. (2020b): Evaluación del impacto del brote de COVID-19 en el turismo internacional [Oficial]. UNWTO - Organización Mundial del Turismo. https://www.unwto. org/es/evaluacion-de-la-incidencia-del-brote-del-covid-19-en-el-turismo-internacional

UNWTO. (2020c): Healing Solutions for tourism challenge. UNWTO - Organización Mundial del Turismo. https://www.unwto.org/healing-solutions-tourism-challenge?f bclid=IwAR2Hy5xXLCKIJZUPxPC87pjHVLZaUE83hGfw-NEXaNYf_NoI1VIwXQxlzX4

UNWTO. (2020d): Supporting jobs and economies through travel \& tourism: A call for action to mitigate the Socio.Economic Impact of COVID-19 and accelerate recovery. UNWTO. https://webunwto.s3 .eu-west-1 .amazonaws.com/s3fs-public/2020-04/ COVID19_Recommendations_English_1.pdf

VALDERRAMA, B. (2019): “Transformación digital y organizaciones ágiles", AranduUTIC. Revista Científica Internacional de la Universidad Tecnológica Intercontinental, vol. 6 (1), pp. 15-50.

VARGAS-SÁNCHEZ, A. (2020a): El turismo post-coronavirus (i). Hosteltur. https:// www.hosteltur.com/comunidad/003943_el-turismo-post-coronavirus.html 
VARGAS-SÁNCHEZ, A. (2020b): El turismo post-coronavirus (ii). Hosteltur. https:// www.hosteltur.com/comunidad/003955_el-turismo-post-coronavirus-ii.html

VARGAS-SÁNCHEZ, A. (2020c): El turismo post-coronavirus (iii). Hosteltur. https:// www.hosteltur.com/comunidad/003961_el-turismo-post-coronavirus-iii.html

VENTAYNOL, G. (2020): Gabriel Escarrer: «La UE debe crear el pasaporte sanitario para no estigmatizar destinos turísticos». Periódico de Ibiza y Formentera. https://www. periodicodeibiza.es/noticias/baleares/2020/04/19/1158333/entrevista-gabriel-escarrerconsejero-delegado-melia-hotels-international.html

VERA-REBOLLO, J.F. e IVARS-BAIDAL, J.A. (2020): El impacto del COVID-19 en la actividad turística de la Comunitat Valenciana, $\mathrm{n}^{\circ} 1$; Prospect Comunitat Valenciana, $\mathrm{p}$. 10). https://prospectcv2030.com/wp-content/uploads/2020/04/INFORME-TURISMOY-COVID19-CV.pdf 